\title{
Ibilgailu elektrikoen propultsio-sistemak: motor elektrikoak eta horien kontrola
}

\author{
(Electric Vehicle propulsion systems: electric machine \\ technologies and control strategies)
}

\author{
Elena Trancho*, Edorta Ibarra, Nima Sabihi, Iraide López \\ Industria eta Garraioa Saila, Tecnalia Research and Innovation, Derio (Bizkaia) \\ Antoni Arias \\ Universitat Politécnica de Catalunya (UPC), Bartzelona \\ *elena.trancho@tecnalia.com
}

DOI: $10.1387 /$ ekaia.16400

Jasoa: 2016-04-01

Onartua: 2016-05-26

Laburpena: Ibilgailu elektriko eta hibridoetako propultsio-sistemetan erabiltzen diren motor elektrikoen artearen egoera aztertzen du artikulu honek. Horrez gain, makina horiek kontrolatzeko ohikoak diren FOC (Field Oriented Control) eta DTC (Direct Torque Control) kontrol-egiturak azaltzen eta konparatzen dira, eta baita motorraren posizio eta abiadura mekanikoa neurtzen duen sentsorerik gabeko kontrola (sensorless, ingelesez) ere: behatzaileetan oinarritutako estimadoreak, abiadura moderatu eta altuetarako baliagarriak direnak, eta salientzia magnetikoan oinarritutako metodoak, abiadura baxu edota ibilgailua geldi dagoenean ezartzen direnak. Amaitzeko, teknologiak etorkizunean izan ditzakeen erronkak eta joerak azaltzen dira.

Hitz-gakoak: Ibilgailu elektrikoa, motor elektrikoak, sentsorerik gabeko kontrola.

\begin{abstract}
This article provides a state of the art of the electric machine technology used in Electric and Hybrid Electric Vehicle applications. Most common FOC (Field Oriented Control) and the DTC (Direct Torque Control) strategies are explained and compared. Position and speed sensorless control strategies are also detailed: observerbased estimators, suitable for medium/high speed ranges and magnetic saliency based methods, applicable for low speeds and standstill operation. Finally, challenges and future trends of this technology are provided.
\end{abstract}

Keywords: Electric vehicles, electrical machines, sensorless control. 


\section{SARRERA}

Kutsadura eta aldaketa klimatikoa direla bide, energia era eraginkorrean kudeatzen dituzten sistemak ikertzeari ekin diote, azken urteotan, komunitate zientifikoak eta industriak. Automobilaren industria da sektore horietako bat; ibilgailuen elektrifikazioak ikerketarako aukera eta erronka berriak sortu ditu, bai makina elektrikoen diseinuan eta baita horien kontrolean ere $[1,2,3]$.

Ibilgailu baten trakzio-sistemaren elektronikaren ikuspuntutik, ibilgailuak dituen funtzio nagusiak erakusten ditu 1. irudiak. Hainbat Kontrolerako Unitate Elektronikok (ECU, Electronic Control Unit) osatzen dute ibilgailuaren kontrol-elektronika. Horien artean, ECU zentrala (BCM, Body Control Module ere esaten zaio) nabarmentzen da. Argiak, klimatizazioa, lehioak, etab. kontrolatzen ditu unitate digital horrek. Horrez gain, beste funtzio batzuk dituzten ECUak monitorizatzen eta kontrolatzen ditu. Unitate elektroniko horien arteko komunikazioa CAN (Controller Area Network) protokolo bidez gauzatzen da. Bestalde, lau ECU nagusi ditu ibilgailuaren propultsioaz arduratzen den potentzia-trenak: bateria-kudeatzailea, transmisio-kontrola, potentzia-trenaren kudeaketa- eta monitorizazio-kontrola (PM \& SUPC, Powertrain Management and Supervisory Control) eta makina elektrikoaren kontrol-unitatea. Azken ECU horren funtzioa da, PM \& SUPC unitateak aginduta, ibilgailua higitzen duen makina elektrikoaren momentu elektromagnetikoa kontrolatzea.

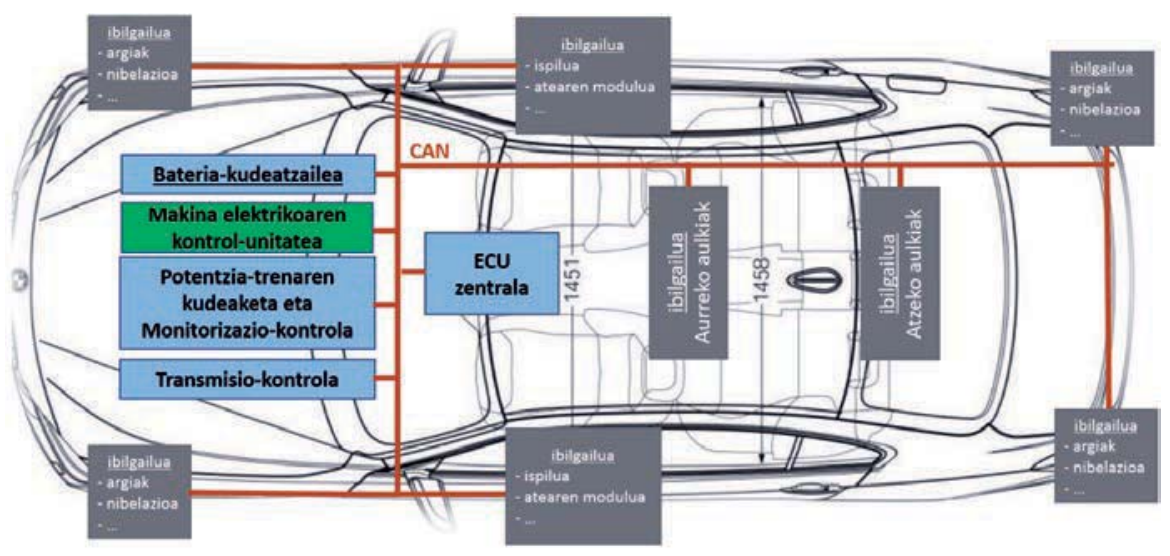

1.irudia. Ibilgailu elektriko baten arkitektura elektronikoa.

Potentzia-sistemari dagokionez, hiru elementu nagusik osatzen dute ibilgailuaren propultsio-trena (2. irudia). Alde batetik, bateriek edota ultrakapazitoreek metatzen dute propultsio-sistemak beharrezkoa duen energia. 
Bestalde, potentzia-bihurgailua beharrezkoa da bateriaren eta makina elektrikoaren arteko interfaz modura. Kasu honetan, baterien DC tentsioa alterno bihurtzea du helburu potentzia bihurgailuak. Funtzio hau betetzen duenean, inbertsore izena ere ematen zaio potentzia bihurgailuari. Oro har, bi mailadun inbertsoreak erabili ohi dira, salbuespenak salbuespen, potentzia-bihurgailu modura (baterien tentsio-mailek ez dute maila anitzeko bihurgailuen erabilera justifikatzen, horiek duten konplexutasun gehigarria dela eta). Azkenik, PWM kontrol-seinaleen bitartez, makina elektrikoaren kontrol-unitateak $U V W$ faseetan tentsio elektriko egokia izatea ahal-bidetuko du, AC makina elektrikoak ibilgailuaren gurpiletan beharrezkoa den momentu elektromagnetikoa sortu dezan ibilgailuaren abiadura-eremu osoan zehar.

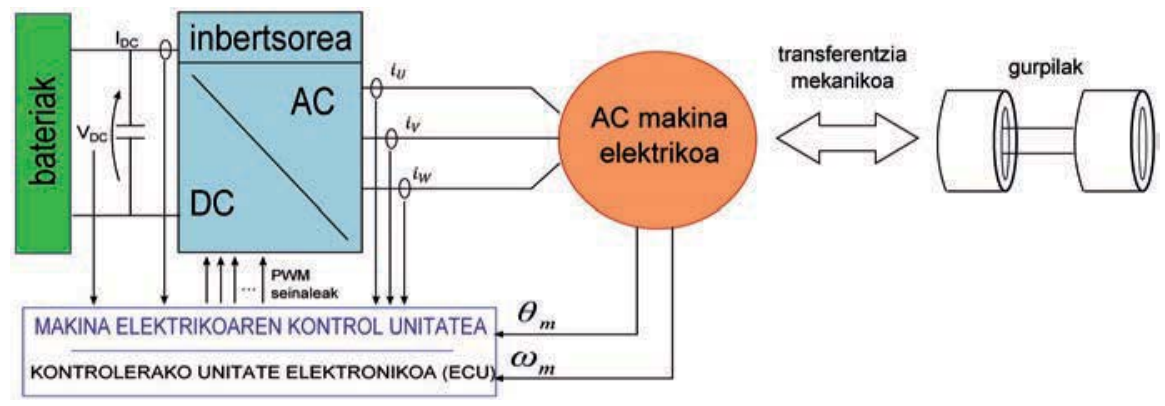

2. irudia. Trakzio elektrikoa ahalbidetzen duen potentzia-sistema eta kontrolunitatea.

Kontuan izan behar da ibilgailu elektriko baten propultsio-sistema bidirekzionala dela, hau da, energiaren norantza baterietatik motorrerantz (motor-operazioa) edota aurkako norantzan (sorgailu-operazioa edota balaztatze elektrikoa) bidera daitekeela, aldiuneko operazio-moduaren arabera. Balaztatze elektrikoari esker energia berreskura daiteke baterietan, honela ibilgailuaren autonomia luzatuz.

Makina elektrikoa da propultsio-sistemaren elementu garrantsitsuenetakoa. Makina-motaren eta konfigurazioaren arabera finkatzen da beharrezkoak diren potentzia-elektronika eta kontrola. Jarraian, elementu horren inguruan sakonduko da.

\section{MAKINA ELEKTRIKOAK IBILGAILU ELEKTRIKOETAN}

\subsection{Sarrera}

Aplikazioaren eskakizunen arabera aukeratu behar da makina elektriko mota eta horren ezaugarriak. Ibilgailu elektriko eta hibridoetan, hu- 
rrengo faktoreak hartu behar dira kontuan makinaren diseinuan edota aukeraketan: momentu/abiadura kurbaren espezifikazioa, eraginkortasuna (ibilgailuaren autonomia luzatzeko edota baterien bolumena murrizteko), gainkargak onartzeko gaitasuna, bolumena eta pisua (energia-dentsitate altua) eta fidagarritasuna $[4,5,6]$. Horrez gain, sistemaren prezioa oso garrantzitsua da automobilaren sektorean, azken hori faktore oso erabakigarria izanik.

Ibilgailu elektrikoetan erabiltzeko interesgarriak izan daitezkeen motormotak biltzen dituzte 3. eta 4. irudiek. Errotorea eta estatorea dira makina elektrikoa osatzen dituzten osagai nagusiak. Estatorea makinaren atal estatikoa da; aldiz, rotorea parte mugikorra. Oro har, AC motako makina trifasikoak (hiru fasekoak, alegia) erabili ohi dira ibilgailu elektrikoen motor modura. Fase anitzeko motorrak ere erabil daitezke, motor elektrikoak jasan behar dituen potentzia-mailak konfigurazio trifasikoarentzat gehiegizkoak direnean, edota sistemak hutsegite-tolerantzia beharrezkoa duenean. Alde horretatik, fase anitzeko hainbat konfigurazio aurki daitezke literatura zientifikoan, bakoitza bere ezaugarriak dituela $[7,8,9]$.

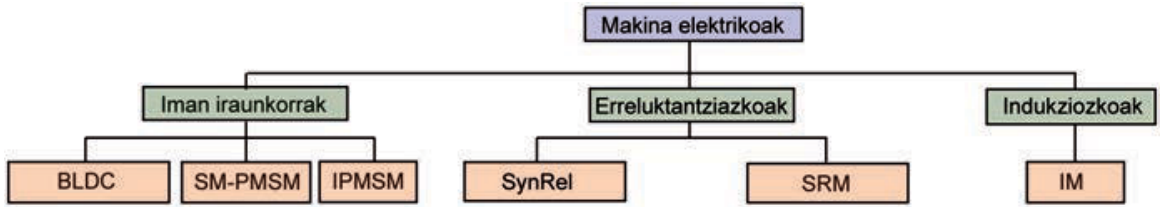

3. irudia. Ibilgailu elektrikoen propultsio-sistemetarako makina elektriko ohikoenen sailkapena.

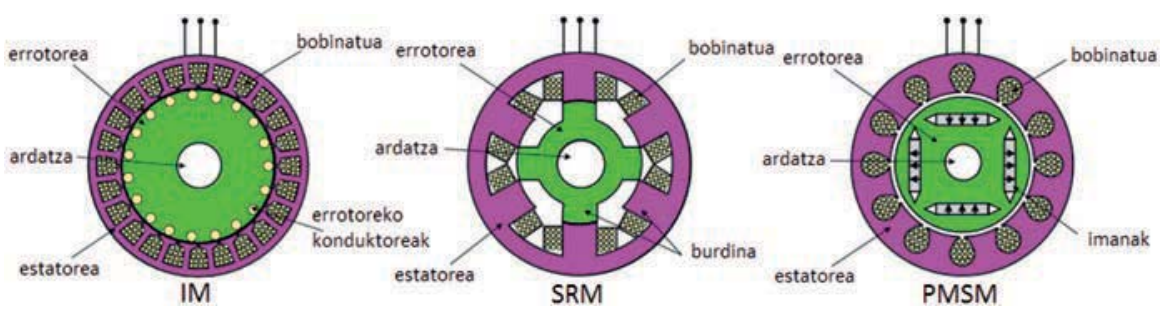

4. irudia. Ibilgailu elektrikoen propultsio-sistemetarako makina elektriko ohikoenen egitura.

Jarraian, aipatutako makina elektrikoen azterketa egiten da familiaren erabera, eta makina horien abantailak eta desabantailak aztertzen dira ibilgailu elektriko eta hibridoaren testuinguruan. 


\subsection{Indukzio-makinak}

Gaur egun, AC makina elektrikoen artean heldutasun-maila altuena duen teknologia da indukzio-makina. Squirel-cage motako makina da (4. irudia), hain zuzen ere, automobilaren industrian arretarik handiena sortu duen induzio-makina, prezioa, sinpletasuna eta fidagarritasuna direla bide [10]. Makina horrek magnetizazio-korronte baxua behar du eremuahultzearen (field weakening, ingelesez) operazio-eremuan. Kobre-galerak (nagusiak direnak makina-mota horretan) murriztu egiten dira eremu horretan; beraz, makinaren eraginkortasuna hobetu egiten da abiadura altuetan. Ordainetan, errotorean sortzen diren galera gehigarriek makinaren eraginkortasuna murrizten dute abiadura nominalaren inguruan [11]. Horrez gain, beste zenbait desabantaila ditu makina-mota horrek, hala nola gainkargan operatzeko limitazioak, bero-galera gehigarriak makinako errotorean eta aire-hutsune txiki baten beharra (magnetizazio-korronteak murrizte aldera) [11].

Indukzio-makina trifasikoaren estatoreko tentsioak horrelaxe adieraz daitezke:

$$
\mathbf{v}_{\mathrm{s}}=\mathbf{R}_{\mathrm{s}} \mathbf{i}_{\mathrm{s}}+\frac{d \Psi_{\mathrm{s}}}{d t},
$$

non $v s=\left[v_{U}, v_{V}, v_{W}\right]^{T}$ estatoreko tentsioak diren, $\mathbf{i}_{\mathrm{s}}=\left[i_{U}, i_{V}, i_{W}\right]^{T}$ estatoreko korronteak diren, $\mathbf{R}_{\mathrm{s}} 3 \times 3$ dimentsioko erresistentzien matrize diagonala den eta $\boldsymbol{\Psi}_{\mathrm{s}}=\left[\Psi_{U}, \Psi_{V}, \Psi_{W}\right]^{T}$ estatoreko fluxu-lotura (flux linkage, inglesez) den:

$$
\boldsymbol{\Psi}_{\mathrm{s}}=\mathbf{L}_{\mathrm{s}} \mathbf{i}_{\mathrm{s}}+\mathbf{M}_{\mathrm{sr}} \mathbf{i}_{\mathrm{r}}
$$

non $\mathbf{L}_{\mathrm{s}}$ estatoreko induktantzia-matriziea den, $\mathbf{M}_{\mathrm{sr}}$ elkarrekiko induktantzia-matrizea den eta $i_{r}$ errotorreko korronte-bektorea den. Indukzio-makinak sortutako momentu elektro-magnetikoa horrelaxe lortzen da:

$$
T_{e m}=\frac{3}{2} P\left\{\Psi_{\mathrm{s}} \times \mathbf{i}_{\mathrm{s}}\right\} .
$$

Indukzio-makinak hainbat ibilgailu elektriko eta hibridotan erabiltzen dira, hala nola Tesla Roadster, Think Ccity, GM EV1, Ford Electric Ranger Pickup, Renault Kangoo, Chevrolet Silverado, Daimler Chrysler Durango eta BMW 5 autoetan [2].

\subsection{Iman iraunkorreko makina sinkronoak}

Gaur egun, iman iraunkorreko makinak (PMSM, Permanent Magnet Synchronous Machine, 4. irudia) DC eta indukzio-makinak ordezkatzen ari 
dira hainbat aplikaziotan. Indukzio-makinek aluminiozko edota kobrezko eroaleak dituzte errotorean, eta errotoreko fluxu magnetikoa indukzio bidez sortzen da. Aldiz, errotorean muntatutako iman iraunkorrek sortzen dute errotoreko fluxu magnetikoa PMSM motako makinetan, inongo eszitazioren beharrik gabe. Hauexek dira makina-mota horren abantailak: potentzia-dentsitate handia, momentu/inertzia ratio handia ${ }^{1}$, momentu elektromagnetiko leuna sortzeko gaitasuna (oso uhindura baxua lortuz sortutako momentuan), operazio-abiadura eremu zabala eta eraginkortasun- eta potentzia-faktore altuak. Indukzio-makinan ez bezala, galera nagusiak estatoreko kobrean sortzen dira; beraz, hozte-sistema sinpleen bidez kanporatu daiteke galerek sortutako beroa.

Hala ere, makina-mota horrek baditu zenbait desabantaila. Makina garestiak dira, potentzia-dentsitate altua ahalbidetzen duten errotoreko imanak eraikitzeko material magnetiko garestiak (lur arraroak) behar baitira. Neodimio-Burdin-Borozko $(\mathrm{NdFeB})$ aleazioak erabiltzen dira, normalean, iman horiek eraikitzeko [2]. Gaur egun neodimioaren prezioa $150 \mathrm{USD} / \mathrm{kg}$ ingurukoa da; nahiz eta prezioak gorabeherak izan, goranzko joera du [2]. Horrez gain, material urria da, eta posible da agortzea edota eskuragarritasun-arazoak izatea, bere erabilera asko zabalduz gero. Azkenik, garrantzitsua da kontuan hartzea material horien monopolioa herrialde gutxi batzuek dutela (Txina da munduko neodimio-esportatzaile garrantzitsuena).

(a) Clarkeren transformazioa

$y$

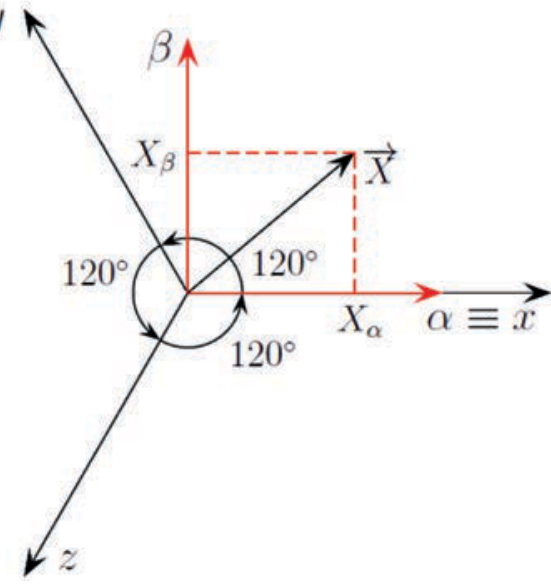

(b) Parken transformazioa

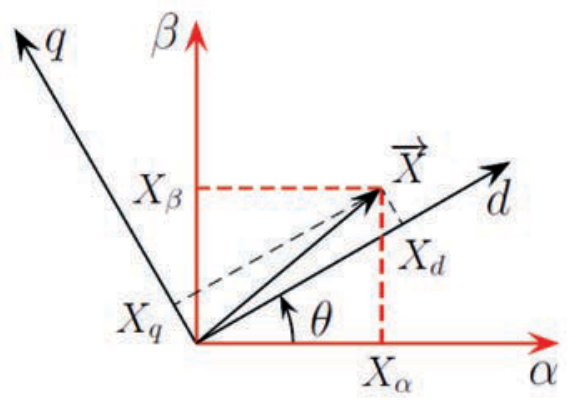

5. irudia. Transformazio bektorialak.

1 Oro har, azelerazio azkarrak ahalbidetzen ditu ezaugarri horrek. Hala ere, ibilgailu elektrikoaren kasuan ez da oso ezaugarri nabarmena, makinak bultzatu behar duen ibiligailuaren inertzia askoz handiagoa delako. 
Teknologia horren bigarren desabantaila nagusia da eremu-murrizketa operazioan korronte gehigarria sartu behar dela makinako estatorean; beraz, makinaren eraginkortasuna murriztu egiten da abiadura altuetan. Hala ere, makina oso eraginkorra da ibilgailuaren abiadura nominalaren inguruan.

Makina sinkronoaren errepresentazio matematikoa gauzatzeko, magnitude trifasioak bi aldagaiko sistema sinkrono batera aldatu ohi da, Clarkeren (4) eta Parken (5) transformazioak (5. irudia) erabiliz.

$$
\begin{aligned}
& {\left[\begin{array}{l}
f_{\alpha} \\
f_{\beta}
\end{array}\right]=\frac{2}{3}\left[\begin{array}{ccc}
1 & -\frac{1}{2} & -\frac{1}{2} \\
0 & \frac{\sqrt{3}}{2} & -\frac{\sqrt{3}}{2}
\end{array}\right]\left[\begin{array}{l}
f_{U} \\
f_{V} \\
f_{W}
\end{array}\right],} \\
& {\left[\begin{array}{l}
f_{d} \\
f_{q}
\end{array}\right]=\left[\begin{array}{cc}
\cos \theta_{m} & \sin \theta_{m} \\
-\sin \theta_{m} & \cos \theta_{m}
\end{array}\right]\left[\begin{array}{l}
f_{\alpha} \\
f_{\beta}
\end{array}\right],}
\end{aligned}
$$

non $\theta_{m}$ erreferentzia-sistema sinkronoaren (errotoreko fluxu magnetikoaren) biraketa-angelua den eta $f$ estatoreko korronte edota tentsioak izan daitezkeen. Horrela, ebatzi beharreko problema matematikoa sinplifikatu egiten da, hiru aldagai aldakorretik bi aldagai estatikora murrizten baita sistema. Horrelaxe emanak datoz PMSM motako makina baten estatoreko tentsioak $d q$ erreferentzia-sistema sinkronoan [12]:

$$
\begin{gathered}
v_{d}=R_{s} i_{d}+L_{d} \frac{d i_{d}}{d t}-\omega_{e} L_{q} i_{q}, \\
v_{q}=R_{s} i_{q}+L_{q} \frac{d i_{q}}{d t}+\omega_{e}\left(L_{d} i_{d}+\Psi_{p m}\right),
\end{gathered}
$$

non $v_{d}, v_{q}, i_{d}$ eta $i_{q}$ estatoreko tentsio eta korronteak diren; $R_{s}, L_{d}$ eta $L_{q}$ estatoreko erresistentzia eta induktantziak diren, $\Psi_{p m}$ iman iraunkorrek sortutako fluxu-lotura den eta $\omega_{e}$ motorraren abiadura elektrikoa den. Makina horrek sortutako momentu elektro-magnetikoa horrelaxe adieraz daiteke:

$$
T_{e m}=\frac{3}{2} P\left\{\Psi_{p m} i_{q}+\left(L_{d}-L_{q}\right) i_{d} i_{q}\right\} .
$$

Beraz, (8)ren arabera, bi osagai ditu momentu elektromagnetikoak: momentu magnetikoa $\left(\frac{3}{2} P \Psi_{p m} i_{q}\right)$ eta momentu erreluktantea 
$\left(\frac{3}{2} P\left(L_{d}-L_{q}\right) i_{d} i_{q}\right)$. Iman iraunkorrek sortutako eremu magnetikoaren eta estatoreko $q$ ardatzeko korrontearen interakzioak sortzen du lehenengo terminoa. Aldiz, makinaren salientziak ( $d$ eta $q$ ardatzen arteko asimetria magnetikoak) sortzen du bigarren terminoa. Errotoreko iman iraunkorren kokapenaren arabera, bi PMSM mota bereiz daitezke:

- Imanak azalean muntatutako PMSM makinak (SM-PMSM, Surface Mounted PMSM, 6. irudia). Izenak ongi adierazten duen bezala, errotorearen azalean kokatzen da material magnetikoa, makina mota horretan. Imanen permeabilitate erlatiboa airearenaren antzekoa denez, magnetizazio-induktantzia berdinak (edo oso antzekoak) dira $\left(L_{d}=L_{q}\right)$. Beraz, fluxu-dentsitate bera dute $d$ eta $q$ ardatzek eta bakarrik momentu magnetikoa sortzeko gai da makina-mota hori.

- Barruan montatutako PMSM makinak (IPMSM, Interior Permanent Magnet Synchronous Machine, 6. irudia). Makina-mota horretan imanak errotorearen barrualdean kokatzen dira, eta zenbait konfigurazio posible daude (6. irudia). Imanak estatoretik urrutiago daudenez, Foucault korronte-galerak txikiagoak dira; ondorioz, imanak demagnetizazio partzialen aurka hobeto babestuta daude. Bestalde, salientzia du makina-mota horrek, eta $d$ ardatzeko erreluktantzia $q$ ardatzekoa baino handiagoa da $\left(L d<L_{q}\right)$. Gauzak horrela, posible da momentu erreluktantea sortzea IPMSM makinen bidez era eraginkorrean, $i_{d}$ eta $i_{q}$ korronteak era egokian kontrolatuz [13].

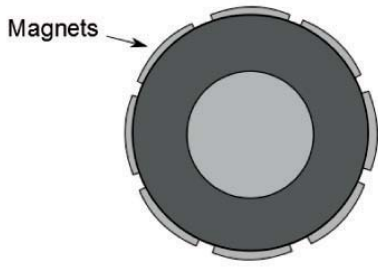

(a) SM-PMSM

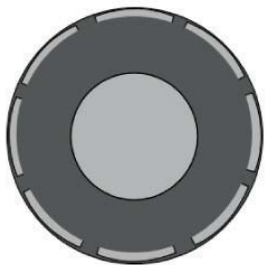

(b) SI-PMSM

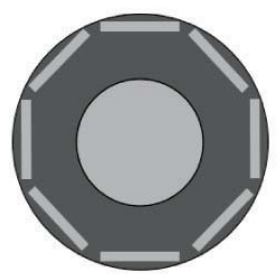

(c) IPMSM

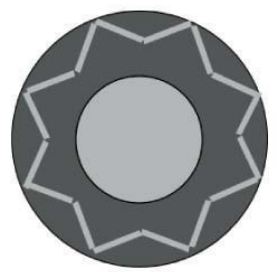

(d) VI-IPMSM

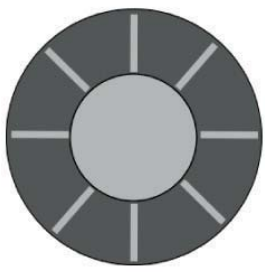

(e) RI-IPMSM

6. irudia. PMSM makinen errotore radialen konfigurazioa iman iraunkorren kokapenaren arabera. 
Oro har, SM-PMSM makinek portaera dinamiko hobea dute, estatoreko inertzia txikiagoa baita. Bestalde, IPMSM makinek unitateko momentu elektromagnetiko gehiago sortzeko gaitasuna dute; horrez gain, eremu-ahulketa gaitasun hobea dute [14]. Arrazoi horiek eta makinaren abantailak kontuan hartuta, IPMSM motako makinak oso egokiak dira ibilgailu elektriko eta hibridoetan erabiltzeko $[5,11]$. Makina-mota hori Toyota Prius eta Camry ibilgailuetan aurki daiteke, besteak beste. Lur arraroek dituzten desabantailak ez badira kontuan hartzen, esan daiteke makina mota hori dela egokiena automobil elektriko eta hibridoetarako.

\subsection{Erreluktantzia sinkronoko makinak}

Erreluktantzia sinkronoko makinak (SynRel, Synchronous Reluctance Machine) PMSM motako makinen imanik gabeko alternatiba dira. Makina horietan errotorea imanik gabe [15] edota lur arraro gabeko imanekin (ferritekin) lagunduta eraikitzen da [16]. Alde horretatik, makina horrek sortzen duen momentu elektromagnetikoa (8) ekuazioak emana dator, non $\Psi_{m} \approx 0$. PMSM motako makinak baino merkeagoa da; horrez gain, tenperatura oso altuak dituzten inguruneetan lan egiteko gaitasuna du imanik ez duelako. Hala ere, SynRel makinaren potentzia-dentsitatea PMSM makinarena baino txikiagoa da. Hori dela eta, ibilgailu elektrikoetarako lagungarria suertatzen da SynRel makinari iman batzuk ezartzea energiadentsitatea handitzeko helburuaz. Modu honetara, IPMSM makinarekin konparatuta, \% 75eko potentzia-dentsitatea lor daiteke [17].

Momentu erreluktantea maximizatzeko optimizatzen dira SynRel makinak. Adibidez, $L_{d} / L_{q}$ erreluktantzia-ratioa 1.5-2.5 bitartekoa izan ohi da IPMSM motako makinetan (momentu erreluktantea momentu totalaren $\%$ 50ekoa izan daiteke IPMSM makina batean). Aldiz, erlazio hori 3.5-5 bitarterainokoa izan daiteke SynRel makina batean [2].

Komunitate zientifikoa makina-mota horrekin lanean ari bada ere, momentuz ez dago teknologia hori erabiltzen duen ibilgailu komertzialik. Horretarako arrazoi bat izan daiteke ferritek tenperatura baxuetan lan egitean desmagnetizatzeko duten joera [18].

\subsection{Erreluktantzia kommutatuko makinak}

Erreluktantzia kommutatuko makinek (SRM, Switched Reluctance Machine, 4. irudia) poloak dituzte errotorean eta estatorean (estatoreko poloek bobinatuak dituzte, aurretik azaldutako makina-motak bezalaxe). Estatoreko polo bat elektrikoki kitzikatzean, kitzikatutako polorantz mugitzen hasten da hurbilen duen errotoreko poloa, erreluktantzia minimoa duen posizioaren bila (induktantzia maximoa duen posizioa) [19]. Estatoreko poloak era egokian kitzikatuz kontrola daiteke makina horren momentu elektromagnetikoa. 
SRM motako makinetan, estatoreko fase bakoitzeko tentsioa deskribatzen duen ekuazioa hurrengoa da:

$$
v=i R_{m}+L(\theta, i) \frac{d i}{d t}+K_{B}(\theta, i) \frac{d \theta}{d t} .
$$

non $v$ faseko tentsioa, $i$ faseko korrontea, $R_{m}$ faseko erresistentzia, $L(\theta, i)$ aldiuneko induktantzia eta $K_{B}(\theta, i)$ aldiuneko indar kontraelektroeragilea diren. Momentu elektromagnetikoaren produkzioa horrelaxe adieraz daiteke:

$$
T_{e m}=\frac{i^{2}}{2} \frac{d L}{d t} .
$$

Beraz, (10) ekuazioaren arabera, sortutako momentuak ez du estatoretik zirkulatzen duen korrontearen polaritatearekiko menpekotasunik, baina bai horren magnitudearen karratuarekiko eta induktantziaren aldaketarekiko. Literatura zientifikoan, hiru faseko 6/4, lau faseko 8/6 eta bost faseko 10/8 konfigurazioak dira ohikoenak (7. irudia); horien artean, 8/6 eta 10/8 konfigurazioak jotzen dira egokien ibilgailu elektriko eta hibridoetarako [20]. Ezaugarri hobetuak dituzten topologia aurreratuak ere aurkeztu dira literatura zientifikoan $[21,22]$. Ordainetan, azken horien konplexutasuna eta fabrikazio-kostua altuagoak dira.
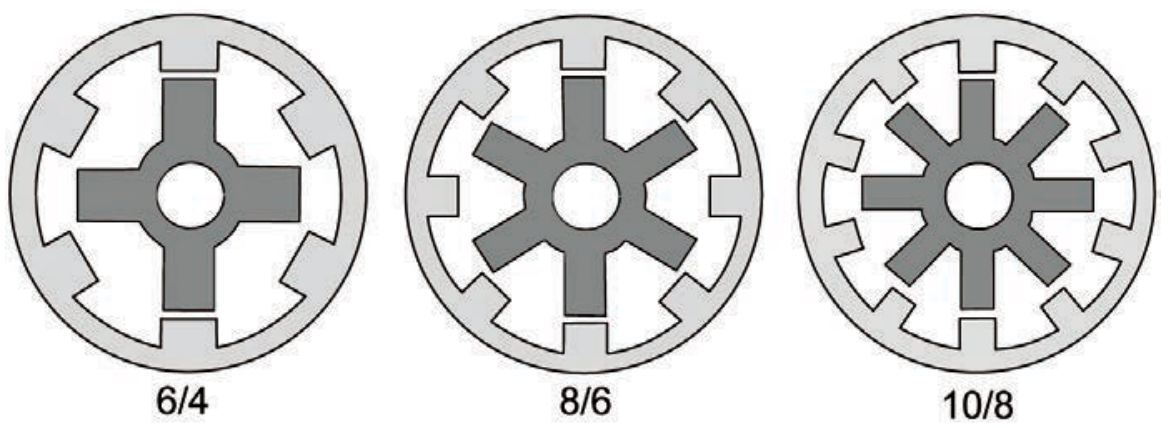

7. irudia. SRM makinaren konfigurazio ohikoenak.

Kostu baxua, fidagarritasuna (fabrikazio-sinpletasunagatik), lur arraroekiko independentzia eta hutsegite-tolerantzia intrinsekoa dira teknologia horren abantaila nagusiak. Hala ere, makina-mota horrek baditu zenbait desabantaila beste teknologiekin konparatuz gero: uhindura oso altua sortzen dute momentu elektromagnetikoan, zarata akustikoa altua da (azken hori abantaila bat izan liteke ibilgailu elektrikoan), ez-linealtasun altua dute 
(makinaren diseinua eta analisia zailtzen dituena) eta potentzia-bihurgailuak jasan behar dituen korronte-mailak handiak dira.

Bi mailadun inbertsoreak erabili ohi dira aurretik azaldutako IM, PMSM eta SynRel makinen potentzia-bihurgailu bezala. H-zubi asimetrikoa da, aldiz, SRM motako makinak elikatzeko erabili ohi den potentziabihurgailuen topologia.

SRM teknologiaren heldutasunak aplikagarria egiten du ibilgailu elektriko komertzialetan. Alde horretatik, Land Rover eta Toyota (Renault-Nissanekin batera) ari dira teknologia horrekin lanean.

\subsection{Makinen teknologien konparaketa eta aplikagarritasuna}

Bibliografia zientifikoaren arabera, IM, PMSM eta SRM motako makinak oso egokiak dira ibilgailu elektrikoetan erabiltzeko. Alde horretatik, horien ezaugarrien arteko konparaketa kualitatiboa erakusten du 1. taulak $[23,11]$.

1. taula. Makina elektrikoen ezaugarrien konparaketa kualitatiboa.

\begin{tabular}{|c|c|c|c|}
\hline Ezaugarria & IM & SRM & PMSM \\
\hline Hutsegite-tolerantzia & baxua & handia & handia \\
\hline Potentzia-dentsitatea & moderatua & moderatua & handia \\
\hline Mardultasuna & handia & handia & moderatua \\
\hline Eraginkortasuna & moderatua & moderatua & handia \\
\hline Prezioa & moderatua & baxua & handia \\
\hline Fidagarritasuna & handia & moderatua & moderatua \\
\hline Momentuaren uhindura & baxua & handia & baxua \\
\hline Zarata akustikoa & baxua & moderatua & baxua \\
\hline
\end{tabular}

Indukzio-makinek eskaintzen dute fidagarritasunik altuena produkziokostu baxuarekin. Nahiz eta makina-mota horren eraginkortasuna ez den PMSM motako makinarenera hurbiltzen, aukera egokia da abiadura altuetan eraginkortasun ona nahi denean. Ordainetan, makinaren potentzia-dentsitate moderatua eta hutsegite-tolerantzia murritza kontuan hartu behar dira.

SRM makina indukzio-makinarekin konpara daiteke potentzia-dentsitateari, efizientziari eta mardultasunari dagokionez. Hala ere, momentu elektromagnetikoan sortzen den uhindura oso nabarmena da (hori litzateke makina-mota horren puntu ahulik nabarmenena) eta kontrola konplexua izan daiteke. 
Azkenik, esan beharra dago PMSM makinek ezaugarri onenak dituztela potentzia-dentsitateari eta eraginkortasunari dagokionez (kontuan izan behar da horiek direla ezaugarri desiragarrienak ibilgailu elektrikoan). Gainera, momentu elektromagnetikoan oso uhindura txikia sortzen du, kontrola era egokian gauzatzen bada. Horrez gain, hutsegite-tolerantzia altua $\mathrm{du}$, teknologia oso mardula baita. Argi geratzen da lur arraroekiko dependentzia dela makina-mota horren desabantaila nagusia.

Adibidez, ezaugarri baliokideak lituzketen $50 \mathrm{~kW}$-eko makinetan, SRM makina litzateke aukerarik merkeena kg-ko, eta baita prezio totalari dagokionez [24] erreferentzian egindako analisiaren arabera. Indukzio-makina $\% 50$ bat garestiagoa eta IPMSMa \% 70 bat garestiagoa, gutxi gorabehera ${ }^{2}$. Beraz, esan daiteke PMSM motako makinak gailentzen direla horien ezaugarriak globalki aztertzen badira. Hala ere, IM eta SRM makinak oso interesgarriak dira prezio aldetik, propultsio-sistema merkeak eraikitzeko. Azken hori da automobilgintzan faktore garrantzitsuenetakoa. Ibilgailu motak eta merkatuak zehaztuko dute zein litzatekeen kasu bakoitzerako motorrerik egokiena.

\section{MOMENTU ELEKTROMAGNETIKOAREN KONTROLA}

\subsection{Sarrera}

Nahiz eta makina elektrikoen momentu elektromagnetikoaren kontrolerako hainbat estrategia aurki daitezkeen literatura zientifikoan, FOC (Field Oriented Control) eta DTC (Direct Torque Control) teknikak [25] dira erabilienak makina sinkronoak eta indukzio-makinak kontrolatzeko. SRM makinaren kasuan, kontrol-teknika partikularragoak erabiltzen dira.

Jarraian, kontrol-teknika horiek gainbegiratzen dira iman iraunkorreko makina sinkronoen kasu partikularrerako (antzerako funtzionamendua dute estrategia horiek indukzio-makinen kasuan; beraz, artikulu honetan ez dira aztertuko) eta SRM makinarako. Azkenik, posizio-sentsorerik gabeko kontrolerako beharrezkoa den posizio-estimatzaileen artearen egoera laburra aztertuko da.

\subsection{Makina sinkronoen FOC kontrola}

FOC kontrola edota kontrol bektoriala da AC makinak kontrolatzeko teknikarik hedatuena. Makina sinkronoen FOC kontrolari dagokionez, es-

2 Azterketa hori 2010ean egin zen eta prezioek gorabeherak izan ditzakete. Hala ere, erreferentziazko balio egokiak dira konparaketarako. Azterketaren prezioek ez dute makinaren muntaia kontuan hartzen. 
tatoreko korronteak errotoreko fluxu magnetikoarekin batera biratzen den $d q$ erreferentzia-sistema sinkronora aldatzen dira Clarke (4) eta Park (5) transformazioen bidez.

Gauzak horrela, (8)k erakusten duen bezala, momentu elektromagnetikoa era ez-zuzenean kontrolatzen da $d q$ korronteak kontrolatuz (8. irudia). PI erreguladoreak erabiltzen dira erreferentziazko korronteen eta estatorean sortutako korronteen arteko errorea minimizatzeko. $d$ eta $q$ ardatzeko erreguladoreak doitzeko, sistema lehenengo ordenakotzat jotzen da. Beraz, estatoreko (6) eta (7) ekuazioetatik abiatuta eta berdinketa-zeinuaren eskuin aldeko azken terminoak mespretxatuz gero, korrontearen eta tentsioaren arteko transferentzi funtzioak Laplaceren esparruan ondorengoak lirateke:

$$
\frac{I(s)}{V(s)}=\frac{1}{L_{j} s+R_{s}},
$$

non $j=\{d, q\}$ den.

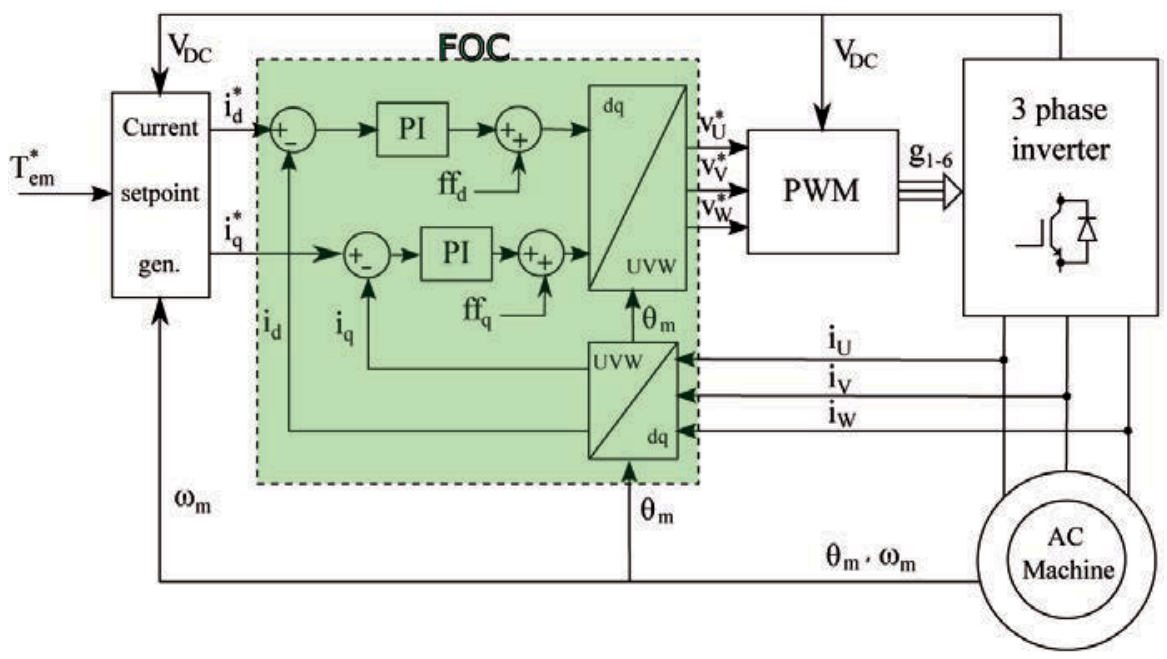

8. irudia. Makina sinkronorako FOC kontrol-diagrama.

Bestalde, sistemaren erantzun dinamikoa hobetzeko, PI kontrolagailuen irteerei gehitzen zaizkie kontrolagailuaren doiketan (6) eta (7) ekuazioetatik mespretxaturiko $f f_{d}$ eta $f f_{q}$ terminoak:

$$
\begin{gathered}
f f_{d}=-w_{e} L_{q} i_{q} \\
f f_{q}=+w_{e}\left(L_{d} I_{d}+\Psi_{p m}\right)
\end{gathered}
$$


Behin inbertsoreak ezarri behar dituen erreferentziazko tentsioak $d q$ ardatzean zehaztuta, (4) eta Park (5) ekuazioetako Clarkeren eta Parken alderantzizko matrizeen bitartez, estatoreko terminaletan aplikatu beharreko $v_{U}^{*}, v_{V}^{*}, v_{W}^{*}$ tentsioak kalkulatzen dira. Pultsu zabalerako modulazioa (PWM, Pulse Width Modulation ) edo modulazio bektoriala (SVM, Space Vector Modulation ) erabiltzen dira, azkenik, inbertsorearen irteeretan erreferentziazko tentsioak sintetizatzeko [26].

$i_{d}^{*}$ eta $i_{q}^{*}$ korronte-erreferentzia optimoak ( 8 irudia) kalkulatu egin behar dira lortu nahi den momentu elektromagnetikoa era eraginkorrean lortzeko. Horrez gain, kontuan izan behar da estatorean ezar daitekeen tentsioa inbertsorearen sarrerako tentsioak mugatzen duela, eta, hala, makinaren abiadura igotzean murrizten doan egonkortasun-eremu bat sortzen da:

$$
L_{d}^{2}\left(i_{d}+\frac{\Psi_{p m}}{L_{d}}\right)^{2}+L_{q}^{2} i_{q}^{2} \leq\left(\frac{V_{\max }}{w_{e}}\right)^{2},
$$

non Vmax estatorean ezar daitekeen tentsio maximoa den $\left(V_{D C} / \sqrt{3}\right.$ modulazio bektoriala erabiltzen denean). Eremu-ahultzearen bidez [27, 28, 13] posible da makina (14) ekuazioak ezarritako limiteen barruan matentzea eta makina abiadura altuetan kontrolatzea.

\subsection{Makina sinkronoen DTC kontrola}

FOC kontrolean ez bezala, Tem momentu elektromagnetikoa eta $\Psi_{S}$ fluxua zuzenean kontrolatzen dira DTC teknikaren bidez (9. irudia). Teknika horretan, aldiune bakoitzean egokiena den kommutazio-egoera aukeratzen da inbertsorean; beraz, ez da estatoreko korronte-erregulatzailerik behar $[29,30]$.

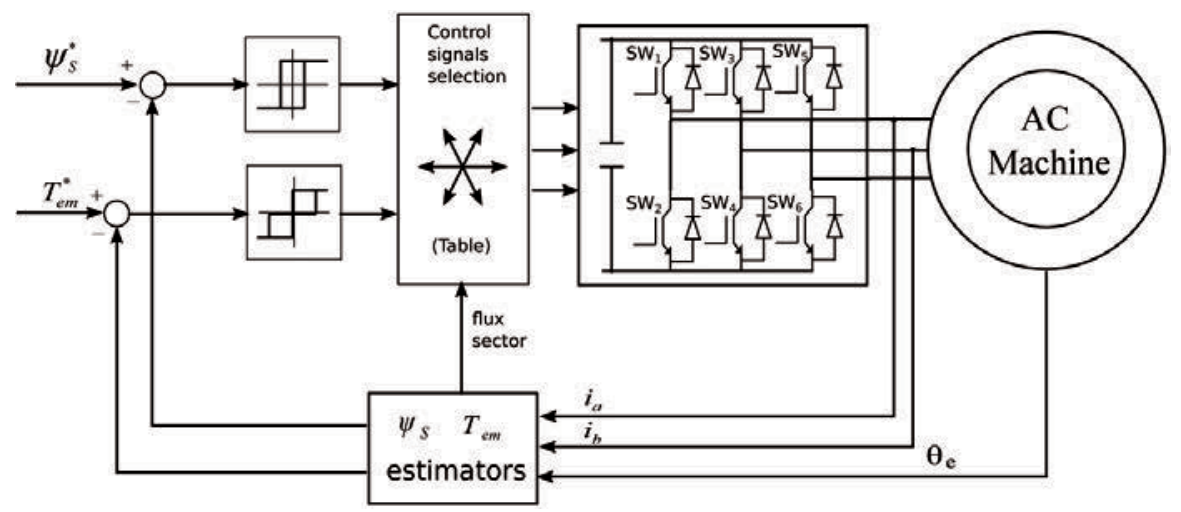

9. irudia. DTC kontrolaren egitura orokorra. 
Kontrol-egitura horretan, makinaren fluxua (15)-(16) eta momentu elektromagnetikoa (8) estimatu behar dira, lehenik eta behin. Ibilgailu elektrikoetan erabiltzen diren makinetan saturazio magnetikoaren eragina garrantzitsua izan daitekeenez, makinaren karakterizazio egokia izan behar da fluxua eta momentua zehaztasunez estimatzeko.

$$
\begin{gathered}
\Psi_{q}=L_{q} i_{q} ; \quad \Psi_{d}=L_{d} i_{d}+\Psi_{p m} \\
\Psi_{s}=\sqrt{\Psi_{d}^{2}+\Psi_{q}^{2}} .
\end{gathered}
$$

Estimatutako fluxua eta momentua erreferentziazko balioekin konparatzen dira. Erreferentziazko momentu/fluxu balioak eraginkortasun maximoko eta eremu-ahultzeko operazio-puntuak dituzte kontuan. Lortutako errore-seinaleak bi eta hiru mailako histeresi-kontrolgailuetan sartzen dira (momentua bi mailako histeresi-kontrol baten bidez kontrolatzea ere posible da [31]). Histeresi-blokeen irteerak eta estatoreko fluxuaren posizioa (errotorearen angelua) erabiltzen dira bihurgailuaren etengailuen kommutazio-egoera zehazteko. Beste era batera esanda, aldiune bakoitzean ezarri beharreko tentsio optimoa zehazten da.

Bi mailako inbertsoreen kommutazio-egoerek sei tentsio-bektore aktibo eta bi tentsio-bektore nulu sortzen dituzte $\alpha \beta$ planoan (10. irudia). Tentsiobektoreek 6 sektoretan banatzen dute plano hori $\left(S_{1}-S_{6}\right)$. Fluxu-bektorea dagoen sektorearen arabera eta histeresi-kontrolek zehaztutakoaren arabera aukeratzen da tentsio-bektore optimoa 10. irudiko taularen arabera: fluxua gehitu (FI), fluxua murriztu (FD), momentua gehitu (TI), momentua murriztu (TD) eta momentua mantendu (TE).

(a) Tentsio-bektoreen errepresentazio hexagonala.

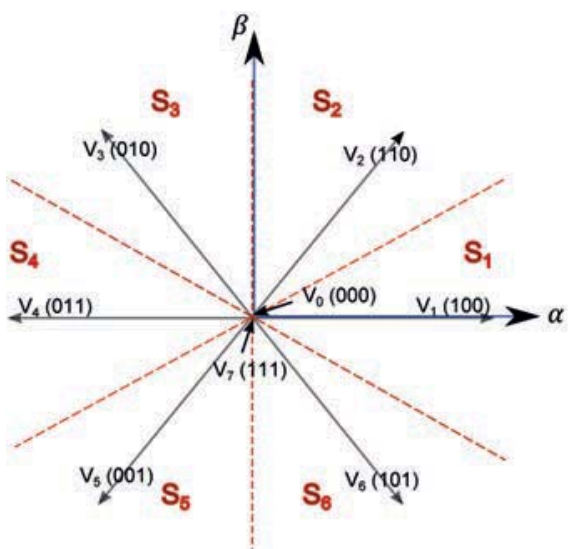

(b) DTC taula konbentzionalak ezarritako tentsio-bektorea, sektorearen eta histeresi-kontrolaren arabera.

\begin{tabular}{|c|c|c|c|c|c|c|c|}
\hline$\Psi_{S}$ & $\mathrm{Tem}$ & $S_{1}$ & $S_{2}$ & $S_{3}$ & $S_{4}$ & $S_{5}$ & $S_{6}$ \\
\hline \multirow{5}{*}{$\mathrm{FI}$} & $\mathrm{TI}$ & $V_{2}$ & $V_{3}$ & $V_{4}$ & $V_{5}$ & $V_{6}$ & $V_{1}$ \\
\cline { 2 - 8 } & $\mathrm{TE}$ & $V_{0}$ & $V_{7}$ & $V_{0}$ & $V_{7}$ & $V_{0}$ & $V_{7}$ \\
\cline { 2 - 8 } & $\mathrm{TD}$ & $V_{6}$ & $V_{1}$ & $V_{2}$ & $V_{3}$ & $V_{4}$ & $V_{5}$ \\
\hline \multirow{5}{*}{ FD } & $\mathrm{TI}$ & $V_{3}$ & $V_{4}$ & $V_{5}$ & $V_{6}$ & $V_{1}$ & $V_{2}$ \\
\cline { 2 - 8 } & $\mathrm{TE}$ & $V_{7}$ & $V_{0}$ & $V_{7}$ & $V_{0}$ & $V_{7}$ & $V_{0}$ \\
\cline { 2 - 9 } & $\mathrm{TD}$ & $V_{5}$ & $V_{6}$ & $V_{1}$ & $V_{2}$ & $V_{3}$ & $V_{4}$ \\
\hline
\end{tabular}

10. irudia. DTC kontrolaren errepresentazio bektoriala eta kommutazio-taula. 


\subsection{FOC eta DTC kontrol-estrategien arteko konparaketa}

Bi kontrol-teknika nagusien ezaugarriak konparatzen dira 2. taulan. Funtsean, portaera hobea du FOC kontrolak korronteen eta momentuaren uhindurei dagokionez. Hala ere, FOCak baino erantzun dinamiko hobea du DTCak, momentua eta fluxua zuzenean kontrolatzen direlako. Parametroen aldagarritasunarekiko mardultasuna da beste puntu positibo bat $[25]^{3}$. Ordainetan, momentuaren uhindura altua da eta kommutazio-maiztasuna aldakorra (histeresi-banden araberakoa). Azken hori ez da oso desiragarria potentzia-elekronikaren ikuspuntutik.

2.taula. FOC eta DTC tekniken arteko konparaketa.

\begin{tabular}{|c|c|c|}
\hline Ezaugarria & FOC & DTC \\
\hline Momentu/fluxu kontrola & zeharkakoa, id eta $i q$-ren bidez & zuzena \\
\hline Konplexutasuna & moderatua & sinplea \\
\hline Momentuaren uhindura & baxua & altua \\
\hline Ezaugarri dinamikoak & desbideraketak transitorioetan & erantzun dinamiko azkarra \\
\hline Mardultasuna & parametroekiko menpekotasuna & Parametroen aldaketekiko mardula \\
\hline Kommutazio-maiztasuna & finkoa & aldakorra \\
\hline
\end{tabular}

\subsection{SRM makinen kontrola}

SRM makinaren momentu elektromagnetikoaren kontrol-estrategiak bi familia nagusitan bana daitezke: kontrol-estrategia zuzenak (DITC, Direct Instantaneous Torque Control) eta ez-zuzenak (IDTC, Indirect Torque Control) [34]. Alde horretatik, DITC kontrolaren egitura erakusten du 11. irudiak. Oro har, SRM makinara moldatutako DTC kontrolaren aldaera da hori, eta makina-mota hori kontrolatzeko dagoen teknikarik sinpleenetakoa da.

DITC kontrolean, SRMaren estatoreko faseetako korronteak eta errotoreko posizioa neurtuz estimatzen da aldiunero fase bakoitza sortzen ari den momentu elektromagnetikoa. Makinaren portaera ez-lineala denez, taule$\tan$ (LUT, Lookup table) gordetako informazio elektromagnetikoaren bidez gauzatzen da momentu magnetikoaren estimazioa; horixe da $T_{e m}=f\left(i, \theta_{m}\right)$. Ondoren, fase bakoitzerako erreferentziazko momentu elektromagnetikoaren eta estimatutako momentuaren arteko errorea kalkulatzen da. Histeresikontrol unitatearen bidez (11. irudia) zehazten dira errore hori zero egiteko beharrezkoak diren PWM seinaleak.

${ }^{3}$ Hala ere, garrantzitsua da kontuan hartzea DTCan erreguladoreek independentzia hori badute ere, makinaren ezagutza zehatza beharrezkoa dela, erreferentziazko momentuaren eta makinaren abiaduraren arabera momentu/fluxu bikote egokia aukeratzerakoan edota momentu/fluxu estimazioan. 


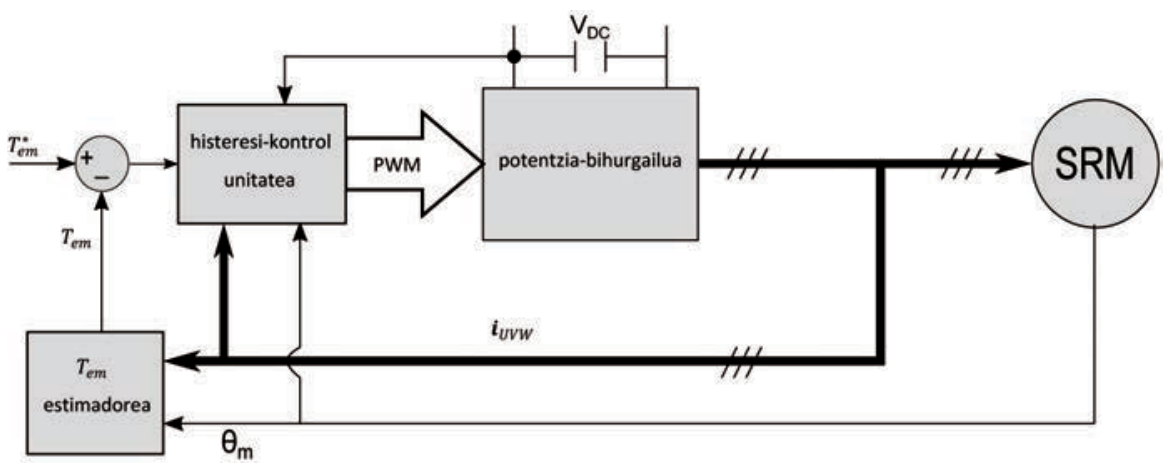

11. irudia. SRMaren DITC kontrol-egituraren oinarrizko diagrama.

\subsection{Kontrol-teknika aurreratuak: sentsorerik gabeko kontrola}

AC makinen kontrol bektorialak eta DTC kontrolak errotoreko posizioaren ezagutza behar du, dagozkion transformazio bektorialak gauzatzeko (8. eta 9. irudiak). Normalean, sentsoreak erabiltzen dira posizio hori zehazteko, hala nola posizio-kodetzaile (encoder, ingelesez) absolutu edo erlatiboak eta kodetzaile angeluar analogikoak (resolver, ingelesez), besteak beste. Sentsore horien erabilerak makinaren kostua eta tamaina handitzen dute [32, 33]. Horrez gain, momentu elektromagnetikoaren kontrola ezingo litzateke gauzatu hutsegite bat gertatzen bada posizio-sentsorean. Arrazoi horiek guztiak direla eta, ikerketa asko egin da sentsorerik gabeko kontrol-estrategiak garatzeko.

Literaturaren arabera, bi taldetan sailka daitezke posizioa (eta abiadura) zehazteko erabil daitezkeen estimazio-estrategiak [35, 3]: behatzaileetan oinarritutako estrategiak (abiadura moderatu eta altuetan lan egin dezaketenak) eta salientzia magnetikoan oinarritutako metodoak (abiadura baxuetan edota makina geldi denean ezarri beharreko teknikak). Ibilgailu elektrikoek geldiunetik abiadura altuetara lan egin behar dutenez, bi teknika horiek konbinatu behar dira, bakoitza dagokion abiadura-eremuan, makina sentsorerik gabe kontrolatu ahal izateko.

- Behatzaileetan oinarritutako estrategiak. Funtsean, indar kontraelektroeragilearen estimazioan oinarritzen dira teknika horiek. Indar kontraelektroeragilearen magnitudea abiadurarekiko proportzionala denez, estimatzaile horiek ezin dezakete zehaztasunez estimatu abiadura baxuetan [36, 37]. Kalman iragazki hedatua (EKF, Extended Kalman Filter) da posizioa estimatzeko erabiltzen den teknikarik ezagunena [38, 39]. Sistema ez-linealentzako estimazio-teknika optimoa da EKF algoritmoa. Teknika oso mardula da, eta kontrolabilitatea ziurtatzen du ingurune zaratatsuetan (zarata elektromagneti- 
koak perturbazioak sortzen ditu magnitude elektrikoen neurketetan). Arrazoi horregatik da hain erabilia makinen sentsore gabeko kontrolean. Hala ere, teknika horren karga konputazionala altua da, eta beharrezkoak dituen parametroen doiketa konplexua. EKF metodoaz gain, beste aukera batzuk aurki daitezke literatura zientifikoan posizioaren estimaziorako, hala nola SMOetan (Sliding Mode Observer) [40, 41] eta PLLetan (Phase Lock Loop) $[42,43]$ oinarritutakoak.

- Salientzian oinarritutako estrategiak. Lehen aipatu bezala, aurreko metodoak ez dira erabilgarriak makinaren abiadura txikia denean. Kasu horietan, salientzia magnetikoan ( $d$ eta $q$ ardatzen arteko erreluktantzia-ezberdintasuna) oinarritutako teknika baten bidez gauzatu ohi da estimazioa ${ }^{4}$. Funtsean, maiztasun altuko $\left(w_{H F}\right) v_{H F}$ tentsioak injektatzen dira, teknika hori erabiltzen denean, makinaren estatorean $[3,44]$ :

$$
\mathbf{v}_{H F}=\left[\begin{array}{c}
v_{\alpha} \\
v_{\beta}
\end{array}\right]=V_{H F}\left[\begin{array}{c}
-\sin \left(w_{H F} t\right) \\
\cos \left(w_{H F} t\right)
\end{array}\right] .
$$

Aipaturiko maiztasun altuko tentsioak hurrengo korronteak sortzen ditu estatorean:

$$
\mathbf{i}_{H F}=\left[\begin{array}{c}
i_{\alpha} \\
i_{\beta}
\end{array}\right]=\left[\begin{array}{c}
I_{0} \cos \left(w_{H F} t\right)+I_{1} \cos \left(2 \theta_{r}-w_{H F} t\right) \\
I_{0} \sin \left(w_{H F} t\right)+I_{1} \sin \left(2 \theta_{r}-w_{H F} t\right)
\end{array}\right] .
$$

Beraz, errotorearen angeluaren posizioari buruzko informazioa eskuratu daiteke neurtutako korronteak era egokian prozesatuz gero [44].

Maiztasun altuko tentsio horiek uhindura sortzen dute estatoreko korronteetan eta momentu elektromagnetikoan [45]. Maiztasun altuko perturbazioak direnez, makinak ez du mekanikoki perturbazio hori jarraitzeko gaitasunik, eta makinaren funtzionamendu mekanikoa bere horretan mantentzen da. Hala ere, makinaren galerak gehitu egiten dira.

${ }^{4}$ Teknika horiek SM-PMSM motako makinetan erabilgarriak izan daitezen, $d$ ardatzarekin alineatuta dagoen errotoreko imanen fluxu magnetikoak $L_{d}$ induktantzian murrizketa nahikoa sortu behar du, saturazio magnetikoaren eraginez, $L_{d}$ eta $L_{q}$ induktantzien artean ezberdintasun nahikoa sortuz. Beraz, SM-PMSM makina partikular batzuetan posible da salientzian oinarritutako estrategiak erabiltzea. 


\section{ONDORIOAK ETA ETORKIZUNERAKO JOERAK IBILGAILU ELEKTRIKOEN PROPULTSIO-SISTEMETAN}

Artearen egoeraren azterketan nabarmendu denez, ibilgailu elektriko eta hibridoetarako gailentzen diren makina elektrikoak IM, SRMa eta PMSMa dira. FOC eta DTC teknikak gailentzen dira kontrolari dagokionez. Teorian, sistema horietan bideragarria da sentsorerik gabeko kontrola gauzatzea gaur egungo DSP eta FPGA modernoei esker, azken urteotan esparru horretan egin diren aurrerakuntzak direla medio.

Nahiz eta azken hamarkadetan asko ikertu den ibilgailu elektriko eta hibridoetarako makina elektrikoetan eta horien kontrolean, ikerketa-lan asko gelditzen da oraindik. Makina elektrikoei dagokionez, topologia eta teknologia berrietan ikertzen jarraitzen da, lur arraroekiko dependentzia murriztu eta makinen ezaugarriak hobetze aldera. Teknologia berri horien adibide dira BLDC motako fase anitzeko makina erreluktanteak (BLDC-MRM, Brushless DC Multiphase Reluctance Machine) eta salientzia bikoitzeko makinak, besteak beste.

Makina elektrikoen operazio-abiadura handitzea da (15.000 rpm edo gehiago) gaur egungo joera nagusietako bat. Makinen abiadura handituz, makinen tamaina murriztu daiteke potentzia bera mantenduz. Horrek inplikazioak ditu makinaren kontrolean, abiadura altuko kontrolak arazoak izan baititzake. Eszenatoki horretara egokitzen diren kontrol-algoritmo berriak garatzea litzateke etorkizunean ikerketa-ildo interesgarri bat.

\section{ESKERRAK}

Hurrengo ikerketa-proiektuek finantziatu dute lan hau: KT4eTRANS (Eusko Jaurlaritzaren ELKARTEK programa, KK-2015/00047), FPGAmc (Eusko Jaurlaritzaren EMAITEK programa), DPI2013-41224-P (Ministerio de Educación) eta 2014 SGR 267 (AGAUR).

\section{BIBLIOGRAFIA}

[1] DELPRAT, S., GUERRA, T.M., RIMAUX, J. 2002. «Optimal control of a parallel powertrain: from global optimization to real time control strategy». IEEE Vehicular Technology Conferenceko aktetan, 2082-2088.

[2] BOLDEA, I., TUTELEA, L., PARSA, L., DORRELL, D. 2014. «Automotive electric propulsion systems with reduced or no permanent magnets: an overview». IEEE Transactions on Industrial Electronics, (61)19, 5696-5711.

[3] OMRANE, I., DIB, W., ETIEN, E., BACHELIER, O. 2013. «Sensorless control of PMSM based on a nonlinear observer and a high-frequency signal 
injection for automotive applications». IEEE Industrial Electronics Society Conferenceko aktetan, 3130-3135.

[4] MISHRA, P., SAHA, S. 2013. «Design modeling and simulation of low voltage squirrel cage induction motor for medium weight electric vehicle». Advances in Computing, Communications and Informaticseko aktetan, 1697-1704.

[5] ASAEI, B., RAHROVI, B. 2010. «Minimum-copper-loss control over full speed range of an IPMSM drive for hybrid electric vehicle application». IEEE Vehicle Power and Propulsion Conferenceko aktetan.

[6] FINKEN, T., HOMBITZER, M. HAMEYER, K. 2010. «Study and comparison of several permanent-magnet excited rotor types regarding their applicability in electric vehicles». Emobility-Electrical Power Train Conferenceko aktetan.

[7] LEVI, E., JONES, M., SATIAWAN, W. 2010. «A multiphase dual-inverter supplied drive structure for electric and hybrid electric vehicles». IEEE Vehicle Power and Propulsion Conferenceko aktetan.

[8] KARTTUNEN, J., KALliO, S., PELTONIEMI, P., SilVENTOINEN, P., PYRHONEN, O. 2013. «Decoupled vector control scheme for dual threephase permanent magnet synchronous machines». IEEE Transactions on Industrial Electronics, (61)5, 2185-2196.

[9] PARSA, L. 2005. «On advantages of multi-phase machines». IEEE Industrial Electronics Society Conferenceko aktetan, 1574-1579.

[10] CHAU, K., LI, W. 2014. «Overview of electric machines for electric and hybrid vehicles». International Journal of Vehicle Design, (64)1, 46-71.

[11] FINKEN, T. HAMEYER, K. 2008. «Comparison and design of different electrical machine types regarding their applicability in hybrid electrical vehicles». International Conference of Electrical Machineseko aktetan.

[12] SEIBT, P., FISCHER, A. 2015. «Description of the cross saturation in an IPMSM for lectric vehicles using bicubic splines». Analysis and simulation of electrical and computer systems, (324)1, 377-381.

[13] MORIMOTO, S., TAKEDA, Y., HIRASA, T., TANIGUCHI, K. 1990. «Expansion of operating limits for permanent magnet motor by current vector control considering inverter capacity». IEEE Transactions on Industry Applications, (26)5, 866-871.

[14] RAHMAN, M.A., ZHOU, P. 1996. «Analysis of brushless permanent magnet synchronous motors». IEEE Transactions on Industrial Electronics, (43) 2, 256-267.

[15] CHEN, C., LIU, T., LIN, M. 2004. «Position control of a sensorless synchronous reluctance motor». IEEE Transactions on Industrial Electronics, (54) $1,15-24$.

[16] GUIGLIEMI, P., PARSTORELLI, M., PELlEGRINO, G., VAGATI, A. 2004. «Position sensorless control of permanent-magnet-assisted synchronous reluctance motor». IEEE Transactions on Industry Applications, (40)2, 615-622.

[17] OOI, S., MORIMOT, M. SANDADA, M. INOUE, Y. 2013. «Performance evaluation of a high power density PMASynRM with ferrite magnets». IEEE Transactions on Industry Applications, (49)3, 1308-1315. 
[18] VAGANTI, A., BOAZZO, B., GUGLIEMI, P., PELLEGRINO, G. «Ferrite assisted synchronous reluctance machines: a general approach». International Conferece on Electrical Machineseko aktetan, (49)3, 1315-1321.

[19] KURIAN, S., NISHA, G.K. 2014. «State of the art of switched reluctance motor for torque ripple minimization». International Journal of Industrial Elecronics and Electrical Engineering, (2)12, 68-74.

[20] PETRUS, C., POP, A.C., LANCU, V. 2010. «Design and comparison of different switchd reluctance machine topologies for electric vehicle propulsion». International Conference on Electrical Machineseko aktetan.

[21] AFJEI, E.S., TOLIYAT, H.A. 2002. «A novel multilayer switched reluctance motor». IEEE Transactions on Energy Conversion, (17)2, 217-221.

[22] OH, S., KRISHNAN, R. 2007. «Two-phase SRM with flux reversal free stator: concept, analysis, design and experimental verification», IEEE Transactions on Industry Applications, (43)5, 1247-1257.

[23] CAO, W., MECROW, B., ATKINSON, G., BENNET, J., ATKINSON, D. 2012. «Overview of elecric motor technologis used for more electric aircraft (MEA)», IEEE Transactions on Industrial Electronics, (59)9, 3523-3531.

[24] DORRELl, D., KNIGHT, A., POPESCU, M., EVANS, L., STATON, D. 2010. «Comparison of different motor design drives for hybrid electric vehicels», IEEE ECCE Conferenceko aktetan, 3352-3359.

[25] GARCIA, X., ZIGMUND, B., TERLIZZI, A., PAVLANIN, T., SALVATORE, L. 2004. «Comparsion between FOC and DTC strategies for permanent magnet synchrnous motors», Advances in Electrical and Electronic Engineering, (76)1, 76-81.

[26] CAPITANEANU, M., DE FORNEL B., FADEL, M., FAUCHER, J., ALMEIDA, A. 2001. «Graphical and algebraic synthesis for PWM methods», EPE Journal, (11)3, 76-81.

[27] JUNG, S., HONG, J., NAM, K. 2013. «Current minimizing torque control of the IPMSM using Ferrari's method», IEEE Transactions on Power Elecronics, (28)12, 5603-5617.

[28] PAN, C., SUE, S. 2005. «A linear maximum torque per ampera control for IPMSM drives over full-speed range», IEEE Transactions on Energy Conversion, (20)2, 359-366.

[29] CHICKHI, A. 2010. «A comparative study of field-oriented control and direct-torque control of induction motors using an adaptive flux observer», Servian Journal of Electrical Engineering, (7)1, 41-55.

[30] HABETLER, T. 1992. «Direct torque control of induction achines using space vector modulation», IEEE Transactions on Industry Applications, (28)5, 1045-1053.

[31] TAKAHASHI, I. 1986. «A new quick-response and high-efficiency control strategy of an induction motor», IEEE Transactions on Industry Applications, (22)5, 820-827.

[32] JOVANOVIC, G., BETZ, R.E., PLATT, D. 1998. «Sensorless vector controller for a synchronous reluctance motor», IEEE Transactions on Industry Applications, (34)2, 346-355. 
[33] PARASITILI, F., PETRELLA, R., TURSINI, M. 2001. «Sensorless speed control of a PM synchronous motor based on sliding mode observer and extended Kalman filter», IEEE Industry Applications Conferenceko aktetan, 533-540.

[34] LEE, D.H., AHN, S.Y., AHN, J.W. «Advanced torque control scheme for the high speed switched reluctance motor,» Intech Open, pp. 87114, 2011.

[35] CHI, S., XU, L. 2006. «Position sensorless control of PMSM based on a novel sliding mode observer over wide speed range», Power Electronics and Motion Conferenceko aktetan.

[36] ZAIM, S., NAHIDMOBARAKEH, B., MEIBODY-TABAR, F. 2014. «Robust position sensorless control of nonsalient PMSM at standstill and low speeds», IEEE Journal of Emerging and Selected Topics in Power Electronics, (2)3, 640-650.

[37] PIIPO, A., HINKKANEN, M., LUOMI, J. 2004. «Sensorless control of PMSM drives using a combination of voltage model and HF signal injection», IEEE Industry Applications Conferenceko aktetan, 964-970.

[38] HUANG, M., MOSES, A., ANAYI, F. 2006. «The comparison of sensorless estimation techniques for PMSM between extended Kalman filter and fluxlinkage observer», Applied Power Electronics Conference and Expositioneko aktetan, 654-659.

[39] JANISZEWSKI, D. 2010. «Extended Kalman filter based speed sensorless PMSM control with load reconstruction», Kalman Filter, 145-160.

[40] QIAO, Z., SHI,K T., WANG, Y., YAN, Y., XIA, C. 2013. «New slidingmode observer for position sensorless control of permanent-magnet synchronous motor», IEEE Transactions on Industrial Electronics, (60)2, 710-719.

[41] LI, R., ZHAO, G. 2009. «Position sensorless control for PMSM using sliding mode observer and phase-locked-loop», Power Electronics and Motion Confereceko aktetan.

[42] KAURA, V., BLASKO, V. 1997. «Operation of a phase locked loop system under distorted utility conditions», IEEE Transactions on Industry Applications, (33)1, 58-63.

[43] OLIVIERI, C., TURSINI, M. 2012. «A novel PLL scheme for a sensorless PMSM drive over common speed reversal problems», International Symposium on Power Electronics, Electrical Drives, Automation adn Motioneko aktetan.

[44] ARIAS, A., ASHER, G., SUMNER, M., WHEELER, P., EMPRINGHAM, L., SILVA, C. 2004. «High frequency voltage injection for the sensorless control of permanent magnet synchronous motors using matrix converters», IEEE Industrial Electronics Conferenceko aktetan.

[45] SILVA, G., ASHER, G., SUMMER, M. 2006. «Hybrid rotor position observer for wide speed-range sensorless PM motor drives including zero speed», IEEE Transactions on Industrial Electronics, (53)2, 373-378. 